\title{
Working Family Caregivers' Perception of Usefulness of an Online Employee Assistance Support Tool: A Pilot Study
}

\author{
Debra Gibbs, Julia Bilotta, Chanté Bowens, Monica Dougherty, Emma Murphy, \\ Nicki Richardson, Molly Schneider-Adams \\ Belmont University, Nashville, USA \\ Email: debra.gibbs@belmont.edu
}

How to cite this paper: Gibbs, D., Bilotta, J., Bowens, C., Dougherty, M., Murphy, E., Richardson, N. and Schneider-Adams, M. (2021) Working Family Caregivers' Perception of Usefulness of an Online Employee Assistance Support Tool: A Pilot Study. Open Access Library Journal, 8: e7663. https://doi.org/10.4236/oalib.1107663

Received: June 19, 2021

Accepted: July 17, 2021

Published: July 20, 2021

Copyright $\odot 2021$ by author(s) and Open Access Library Inc.

This work is licensed under the Creative Commons Attribution International License (CC BY 4.0).

http://creativecommons.org/licenses/by/4.0/

\section{(c) (i) Open Access}

\begin{abstract}
Objectives: The population of older adults is growing rapidly, creating high demand for the involvement of working family caregivers. This concurrent mixed-methods study sought to obtain information from working family caregivers regarding their perceptions of the usefulness of an online employee assistance support tool. Methods: Working family caregivers $(n=15)$ participated in a semi-structured focus group completing a demographic survey and the Modified Caregiver Strain Index (MCSI). Results: Total MCSI score had a statistically significant positive relationship with hours of care provision per week and presented an inverse association with caregiver age. Caregiver age had a statistically significant inverse relationship with the perception of caregiving as confining. Qualitative data identified needs for family caregivers support in three major themes: knowledge, understanding, and connection. Discussion: This study highlights a myriad of caregiver burden experiences and the necessity of various supports for each caregiver's unique situation beyond the traditional workplace polices.
\end{abstract}

\section{Subject Areas}

Geriatrics, Human Resource Management, Social Issues and Public Policy, Sociology

\section{Keywords}

Working Family Caregivers, Caregiver Burden, Older Adults, Caregiver Resources, Aging 


\section{Working Family Caregivers' Perception of Needs and Burden}

Family caregivers are individuals who provide unpaid care for a recipient from either their family of origin, such as a parent or grandparent, or their family of choice, such as a friend, neighbor, or life partner (National Alliance for Caregiving \& Emblem Health, 2010) [1]. In 2015, an estimated 34.2 million American adults served as family caregivers to older adults (AARP \& National Alliance for Caregiving, 2015) [2]. With an estimated sixty percent of family caregivers engaging in full-time employment (AARP \& National Alliance for Caregiving, 2015 [2]; Pew Research, 2018 [3]), the ability to balance the demands of family caregiving with the demands of paid employment, or "work," constitutes one of the challenges faced by those providing unpaid care to an ever-increasing older adult population. Furthermore, an individual's health, well-being, and quality of life can be affected by an overall life balance or imbalance (Matuska \& Barrett, 2014) [4].

Several studies associate family caregiving with increased work interference such as increased absenteeism, work productivity loss, a reduction in work hours, and/or labor market withdrawal, as well as difficulty maintaining lifestyle balance between work and caregiving occupations (Burton et al., 2004 [5]; Calvano, 2013 [6]; Gaugler et al., 2018 [7]; Lilly et al., 2007 [8]; Liu et al., 2017 [9]; Longacre et al., 2017 [10]; Paulson et al., 2017 [11]; Wolff et al., 2016 [12]). For many individuals, the occupation of work is an integral component of lifestyle balance (Fossey, 2019 [13]; Hunt, 2015 [14]).

Engagement in employment has positive effects on health and well-being while also protecting against negative effects of caregiving (Cole et al., 2009 [15]; Hunt, 2015 [14]; Stine-Morrow et al., 2008 [16]).

Caregiving has been identified as having some positive aspects such as increased "sense of self-pride and fulfillment, perceptions of being needed, and opportunities to learn new skills and enhance relationships" (Grossman \& Gruenewald, 2017, p 435) [17]. However, the provision of daily caregiving responsibilities can have negative consequences on one's psychological, physical, and social health (Corvin et al., 2017 [18]; Gray et al., 2007 [19]; Grossman \& Gruenewald, 2017 [17]; Pizzi, 2010 [20]; Schulz \& Eden, 2016 [21]; Schulz \& Tompkins, 2010 [22]). Evidence supports a positive correlation between the hours of care provided and caregiver stress, as family caregivers who provide 36 or more hours of care per week are more likely to experience symptoms of anxiety or depression than non-caregivers (Gray et al., 2007) [19]. Additionally, caregivers who provide care for more hours per week and over a longer duration of time experience greater stress (Halpern et al., 2017) [23]. Elevated levels of emotional stress positively correlate with intensity of caregiving responsibilities, such as co-residence and increased physical care, specifically provision of 3 or more personal care tasks like bathing, toileting, or feeding (Calvano, 2013 [6]; Halpern et al., 2017 [23]; Longacre et al., 2017 [10]; Liu et al., 2017 [9]). 
The degree to which caregiving responsibilities become overwhelming and cause a high degree of emotional stress depends on the individualized experience of the caregiver. Caregiver burden, or a caregiver's subjective response to the physical and/or emotional challenges of the caregiver role (Thornton \& Travis, 2003) [24], is not a uniform experience and can be influenced by secondary stressors unique to each caregiver's personal context, such as paid employment, family conflict, and/or financial resources (Zarit \& Zarit, 2015) [25]. Gaugler et al. (2018) [7] found that family caregivers who reported a greater conflict between caregiving and work responsibilities had worse scores for mental and physical health and that caregiver burden was the strongest indicator of caregiving-work conflict. Thus, caregiver burden influences caregiving-work conflict, which in turn impacts caregivers' emotional stress and mental well-being (Gaugler et al., 2018) [7]. Additional research supports the association between increased caregiving responsibility, work interference, and even early labor force withdrawal (Calvano, 2013 [6]; Longacre et al., 2017 [10]).

To minimize the impact of caregiving-related stressors, family caregivers report using a variety of coping strategies (Barrett, 2013) [26]. Deliberate coping strategies, such as seeking support from others to help with caregiving demands, have been associated with increased life satisfaction and decreased anxiety levels (Cooper et al., 2008 [27]; Sun et al., 2010 [28]). Avoidant coping strategies, such as eating, smoking, or avoiding people, situations, or tough decisions, have been associated with decreased life satisfaction and increased caregiver burden (Sun et al., 2010) [28]. Additionally, family caregivers may use work participation to cope with caregiving-related stressors (Calvano, 2013 [6]; Van Dongen et al., 2014 [29]). Work can mitigate some of the burden felt by family caregivers by providing social interaction, personal achievement, and personal space, or "escape," from the caregiver role (Van Dongen et al., 2014) [29].

Certain governmental and workplace policies also help caregivers balance the conflicting demands of caregiving and employment. Caregivers may utilize federal programs such as the Family and Medical Leave Act (FMLA) and the National Family Caregiver Support Program (NFCSP). The FMLA is a federal law that provides employees who are over the age of sixty or providing care to someone sixty or older with twelve weeks of unpaid, job-protected leave per year (U.S. Department of Labor, 2019) [30]. While FMLA is a practical option for an individual who needs to provide short-term care to a family member, it is not comprehensive for all US workers, fails to provide support for long-term care needs, and is time limited (Yang \& Gimm, 2013) [31]. Due to the fact that the leave covered under the FMLA is unpaid and does not cover all workers, it will not completely resolve the struggle to balance work and caregiving for many family caregivers (Chen, 2016) [32]. Another federal program, the National Family Caregiver Support Program (NFCSP), provides several services to caregivers, including respite, supplemental care services, and individual counseling (Administration for Community Living, 2019) [33]. Unfortunately, the NFCSP 
falls short as the number of potential beneficiaries exceeds the program's capacity (Schulz \& Eden, 2016) [21].

Workplace policies, sometimes known as caregiver friendly workplace policies (CFWPs), aid caregivers in combating the health and financial consequences related to family caregiving. CFWPs may include flexible work schedules, job sharing, the option to work from home, access to compressed work weeks, and permitting allocated days off (Jang et al., 2010) [34]. Two major attributes that contribute to high satisfaction with CFWPs are employment policies that allow flexibility in work scheduling and assignments as well as supportive senior management (Calvano, 2013 [6]; Dembe \& Partridge, 2011 [35]; Gaugler et al., 2018 [7]). Control over one's work schedule and the availability of work-life balance programs are linked to greater job satisfaction and mental well-being among all workers (Jang et al., 2010) [34]. Research supports the idea that employer support of caregiving demands through CFWPs improves employee retention as well as decreases turnover (Ireson et al., 2018) [36].

Recognizing the multidimensional nature of the caregiver role and the challenges that working family caregivers face in maintaining lifestyle balance, this mixed-methods study aimed to assess perceptions of caregiver burden among working family caregivers and perceptions of an online employee assistance support tool developed by a local non-profit agency for aging. The support tool has been designed to be flexible and individualized to the context and needs of the end user. It provides customized resources and factors to consider about aging needs and transitions, including information on housing and placement options, legal and financial considerations, support, and educational resources. All resources and decision considerations are based on answers provided by individual users. Additionally, the support tool offers a consult from a gerontology social work professional to assist in understanding the resources provided and considerations specific to the individual.

The primary research objective was to determine how working caregivers perceive the usefulness of a preliminary model of an online support tool. A secondary research aim was to identify the characteristics of the working caregivers of two local businesses and the level of perceived caregiver burden within the participants. Researchers hypothesized that working family caregivers would provide a variety of responses to the support tool describing their unique roles, caregiving situations, and perceived burden level, and that the support tool would be perceived as a helpful resource.

\section{Methods}

\subsection{Procedure}

A mixed-methods design was used. Qualitative data examined the lived experience and opinions of working family caregivers, while quantitative data surveyed the caregivers' perceived level of strain as well as the relationship between perceived caregiver strain and form(s) of support desired. Prior to commencing 
the study, researchers obtained approval from a university Institutional Review Board [Protocol 791].

Two focus groups were arranged to gather information from working family caregivers in an effort to improve an online employee assistance support tool developed by a local non-profit agency for aging. The agency partnered with two local employer organizations in Middle Tennessee to conduct focus groups of working family caregivers. Participants were provided with access to the online support tool for review and were provided with an individualized report of informational resources based on their responses. Two focus groups, pre-arranged by the agency, were conducted over a span of three weeks and took place on-site at each local organization for one hour each. Prior to the commencement of each focus group, all participants signed an informed consent form to confirm their willingness to participate in a focus group and complete a survey. Each focus group was facilitated by a licensed master social worker with the researchers present to collect data.

At the conclusion of each focus group, participants were asked to complete a short survey consisting of six demographic questions and the Modified Caregiver Strain Index (MCSI). Demographic questions were based on significant caregiving factors as indicated within the literature such as age of the caregiver, age of the care recipient, relationship of the caregiver to the care recipient, residence of care recipient, hours of care provided each week, and duration of caregiving responsibilities as measured in months or years. Participants attending the second focus group were also asked to complete a brief checklist that assessed the perceived usefulness of the specific caregiving resources provided through the online employee assistance support tool.

\subsection{Sample}

Sample selection was based on convenience sampling of working family caregivers from two local companies identified by the local non-profit agency for aging. Recruitment of study participants was done by the employer. Inclusion criteria for caregiver participants was being 18 years old or over, employed, providing care for a family member or friend age 50 years old or over, and the ability to speak and understand English, as no translation services were available for this study. A total of 15 participants were included in the study.

\subsection{Measures/Data Collection}

\subsubsection{Focus Group}

Qualitative data gathered for the study came from focus group participant responses. A trained group facilitator led two employee focus groups (one for each local company) using a semi-structured format, posing a series of questions related to the online support tool to guide the conversation among working family caregivers. During the focus groups the aim was to explore caregiver perception of the usefulness of the online support tool and resources provided. 


\subsubsection{Modified Caregiver Strain Index (MCSI)}

The MCSI was given to the participants to provide a quantitative measure of perceived caregiver strain experienced by the working family caregivers. The 13-item MCSI contains statements such as caregiving is confining, caregiving is a financial strain, or there have been work adjustments (Thornton \& Travis, 2003) [24]. Items screen for strain across five major domains: financial, physical, psychological, social, and personal (Onega, 2008) [37]. Caregivers rank their responses to statements on an ordinal scale ranging from 0 to 2 , where 2 indicates agreement with a statement on a regular basis, 1 indicates agreement with a statement sometimes, and 0 indicates disagreement with a statement. A total score is then calculated by adding all ranked responses. Descriptive categories are not provided to distinguish the level of caregiver strain, requiring a clinician's professional judgment to determine the level of caregiver strain according to total score and to identify "families who may benefit from more in-depth assessment and follow-up” (Onega, 2008, p. 65) [37]. Thornton and Travis (2003) [24] identified the internal reliability for the MCSI as 0.90 .

\subsection{Data Analysis}

\subsubsection{Quantitative Analysis}

Total scores were calculated for each participant's MCSI questionnaire. All demographic data and MCSI content were analyzed using descriptive statistics. Data analysis was conducted using IBM SPSS Statistics (version 25) software and summarized using frequency distributions for nominal and ordinal categorical variables. Median and interquartile range were used to summarize the continuous data due to small sample size. The strength and direction of the associations between continuous and ordinal caregiving variables with the perceived burden of the caregiving (MSCI total score and three components: confining, family adjustments, and work adjustments) were assessed using Spearman's rho coefficients. The associations of where the person being cared for lived (nominal) with those perceived burden variables were assessed using the Kruskal-Wallis test (MSCI total score) and Pearson Chi-Square (MSCI components). An alpha of $0.05(p<0.05)$ was used for determining statistical significance.

\subsubsection{Qualitative Analysis}

All focus group data were analyzed via thematic analysis allowing the investigators to identify patterns of meaning from the complex and detailed perspectives of focus group participants in a rigorous and trustworthy way. Researchers followed the process of thematic analysis as outlined by Nowell et al. (2017) [38]. Trustworthiness of data analysis was ensured by following the criteria of credibility, transferability, dependability, and confirmability as outlined by Lincoln and Guba (1985) [39]. Dependability of data analysis was ensured via an audit trail of records of notes, audio recordings, and transcripts. Techniques utilized to ensure credibility included researcher triangulation. Participant responses 
were transcribed by two researchers. A second group of two researchers read the transcripts identifying and coming to a consensus of themes and definitions. The themes were then reviewed by a third group of two researchers for refinement. Finally, all researchers reviewed the themes for final consensus and clarification on the themes and definitions.

\section{Results}

\subsection{Quantitative Data}

\subsubsection{Sample Characteristics}

Among the 15 participants in this study, the median age was 50 years. A majority cared for someone between 65 and 84 years of age who was a parent or other family member living in their own home. While the number of hours per week spent providing care varied widely, a majority of participants provided care for 20 hours per week or less and for a length of 2 - 4 years. All sample characteristics are summarized in Table 1.

Table 1. Summaries of the sample characteristics.

\begin{tabular}{|c|c|c|}
\hline Characteristic & $\mathrm{n}$ & Median (IQR) \\
\hline Age & 15 & $\begin{array}{c}50(40,59) \\
\mathrm{n}(\%)\end{array}$ \\
\hline Age of person cared for (years) & 14 & \\
\hline $50-64$ & & $1(7)$ \\
\hline $65-74$ & & $6(43)$ \\
\hline $75-84$ & & $5(36)$ \\
\hline$\geq 85$ & & $2(14)$ \\
\hline Relationship & 15 & \\
\hline Spouse & & $1(7)$ \\
\hline Parent/In-Law & & $12(80)$ \\
\hline Other family & & $2(13)$ \\
\hline Where does person live & 15 & \\
\hline With caregiver & & $3(20)$ \\
\hline Own home & & $10(67)$ \\
\hline Other & & $2(13)$ \\
\hline Hours care (per week) & 15 & \\
\hline$<1$ & & $1(7)$ \\
\hline $1-8$ & & $8(53)$ \\
\hline $9-20$ & & $4(27)$ \\
\hline $21-40$ & & $1(7)$ \\
\hline$>40$ & & $1(7)$ \\
\hline Length care & 14 & \\
\hline 6 months - 1 year & & $3(21)$ \\
\hline $2-4$ years & & $5(36)$ \\
\hline 5 - 9 years & & $3(21)$ \\
\hline$\geq 10$ years & & $3(21)$ \\
\hline
\end{tabular}




\subsubsection{MCSI Findings}

The total MCSI scores for the sample were highly variable ranging from 0 to 20 with a median score of 10 . Generally, older caregivers scored lower on the MCSI, reporting lower levels of caregiver strain. Additionally, quantitative analysis revealed a statistically significant inverse association between caregiver age and agreement with the MCSI statement, caregiving is confining $\left(r_{s}=-0.56, p=\right.$ 0.031 ) (Table 2). No statistically significant associations between the age of the person being cared for the length of time spent providing care were observed $(p>0.05)$. However, the more hours per week spent providing care, the higher the participant's total MCSI score $\left(r_{s}=0.87, p<0.001\right)$. The MCSI statement, there have been work adjustments, was significantly associated with providing more hours of care per week and reporting higher levels of caregiver strain $\left(r_{s}=\right.$ $0.75, p=0.001$ ). No statistically significant associations were found between the caregiver's perception of strain and where their care recipient resided. Internal reliability of the MCSI in this study was 0.88 .

\subsection{Qualitative Data}

Overall, focus group participants perceived the employee assistance support tool as a useful resource for supporting their roles as family caregivers. Considering participant responses in aggregate, researchers defined this overarching idea of support as "emotional or practical assistance in performing a life role" and further categorized it into three major themes: knowledge, understanding, and connection.

\section{Theme 1: Knowledge}

The first theme, knowledge, was defined as "the state of knowing about or being familiar with a particular subject” (Knowledge, n.d.) [40]. Two subthemes emerged, the first being knowledge about eldercare terminology. Focus group participants wanted frequently-used eldercare terminology and acronyms, like IADLs and ADLs, defined. One participant wanted more information about the costs, roles, and responsibilities of a geriatric care manager. The second subtheme,

Table 2. Associations of caregiver characteristics with MSCI scores and components $(\mathrm{N}=$ $15)$.

\begin{tabular}{ccccc}
\hline & $\begin{array}{c}\text { Total MCSI } \\
\text { Score }\end{array}$ & Confining & $\begin{array}{c}\text { Family } \\
\text { Adjustments }\end{array}$ & $\begin{array}{c}\text { Work } \\
\text { Adjustments }\end{array}$ \\
\hline Age & -0.41 & -0.56 & -0.37 & -0.34 \\
& $(0.128)$ & $(0.031)$ & $(0.178)$ & $(0.217)$ \\
Age Person & -0.01 & -0.06 & $<0.01$ & -0.07 \\
Cared For & $(0.971)$ & $(0.838)$ & $(0.990)$ & $(0.808)$ \\
Hours Care per & 0.87 & 0.62 & 0.60 & 0.75 \\
Week & $(<0.001)$ & $(0.015)$ & $(0.017)$ & $(0.001)$ \\
Length of Time & 0.34 & 0.37 & 0.32 & 0.35 \\
Giving Care & $(0.222)$ & $(0.187)$ & $(0.265)$ & $(0.227)$ \\
\hline
\end{tabular}

Note. Values in the cells are $r_{s}$ (p-value); ${ }^{*} \mathrm{n}=14$ (one participant did not answer this question). 
knowledge about care needs, referenced the participants' interest in learning about the breadth of care needs. Participants expressed an interest in various living options for older adult loved ones, checklists of important information to consider, and financial information to help plan for care needs.

\section{Theme 2: Understanding}

The meaning of the theme of understanding, as defined by the researchers, is "awareness or insight for the application of knowledge to an individual circumstance", with three subthemes emerging. The first, understanding choices to support decision-making, refers to the participants' interest in an assortment of options that empower them to make an informed decision. Participants noted that the online tool "opens up a bunch of solutions" and "makes suggestions, but you felt that you still have the power to make a decision". The online tool also helped one participant feel reassured about decisions she had already made, stating, "...it lets you know that there are other options out there. You don't have to look at one thing and think, oh I made this wrong decision". Participants' vocalized the importance of recognizing individualized circumstances as the online tool presented information directed toward their specific caregiving situation. In the third subtheme, insight into having hard conversations, participants expressed interest in information about how to have tough conversations with loved ones on topics related to care needs, such as driving and determining when home is no longer the best care option. One participant noted, "It'd be nice to have links [for] difficult conversations. How to start these conversations, either with other members of the family or the person [I'm caring for]".

\section{Theme 3: Connection}

The researchers defined the third theme, connection, as "establishing a link between two or more people, ideas, or services". The first subtheme that emerged was to create new connections for personal support or assistance, wherein participants requested online support or chat groups with fellow caregivers and helpful contact numbers for local organizations like area agencies on aging. In the checklist given to the second focus group, it is relevant to note that all participants displayed interest in the item, finding services to help your loved one or you as a caregiver, including that a phone consultation with a professional would be beneficial. The next subtheme identified was to reinforce existing connections. Participants were interested in sharing information generated by the online tool with the care recipient or other family members who assist with caregiving responsibilities. Participants noted that this information could help facilitate caregiving conversations with all stakeholders. For example, one participant noted that the tool would be useful to "sit down with [her] loved one and easily toggle through it and make it a little less scary as [they] start the planning process". Lastly, many participants expressed interest in connection to outside resources for caregiving, such as a national database of eldercare resources, a directory of firms that specialize in aspects of eldercare law, applicable documents for estate planning or power of attorney, and other relevant services. 


\section{Discussion}

The objective of this mixed-methods study was to explore the perceptions of working caregivers on the usefulness of an online employee assistance support tool. Overall, the results emphasize the need to consider factors related to each family caregiver's unique role and caregiving situation when providing supportive services. A secondary objective was to quantitatively examine factors related to caregiver burden experienced by working family caregivers as a pilot assessment of factors that may be considered in further tool development.

The majority of participants in the present study were similar to the demographic profile of the "typical" caregiver in that they were female, an average age of 50 years old, and employed full time (National Alliance for Caregiving \& AARP Public Policy Institute, 2015) [41]. An important distinction between the working family caregivers in this study was that the majority provided between 1 - 8 hours of care as compared to the "typical" caregiver who provides 20 or more hours of care per week (National Alliance for Caregiving \& AARP Public Policy Institute, 2015 [41]; Schulz \& Tompkins, 2010 [22]). Consistent with the literature, this study found that providing more hours of care per week was associated with increased caregiver burden (Gray et al., 2007 [19]; Halpern et al., 2017 [23]). Additionally, having to make work adjustments to meet caregiving needs significantly contributed to caregiver strain (Longacre et al., 2017 [10]; Gaugler et al., 2018 [7]).

The primary quantitative finding of this study was an inverse association between caregiver age, strain score, and the MCSI variable, caregiving is confining. Younger caregivers noted that caregiving was confining and reported higher levels of burden, whereas older caregivers were less likely to report this. Researchers hypothesize that employed middle-aged adults 45 - 65 years old may find themselves striving to achieve accomplishments that will outlast them (Cronin, 2016) [42]. Often these individuals have more demanding responsibilities, including those related to work and parenting, that may contribute to greater perceived burden. The addition of caregiving for an older adult can further increase perceived burden, as it may conflict with their participation in work and other life activities. Caregiving-work conflict can negatively impact physical and mental health resulting in greater caregiver burden (Gaugler et al., 2018) [7], whereas life balance promotes health and well-being (Cole et al., 2009 [15]; Hunt, 2015 [14]; Stine-Morrow et al., 2008 [16]).

This study was novel in that it considered the opinions of working family caregivers by gathering qualitative information about their perception of the usefulness of a range of support options offered in an online employee assistance support tool. Within the literature, several studies examine the effects of caregiving on workplace factors, but few studies gather qualitative information about the types of support working family caregivers perceive as beneficial. In general, caregivers report needing more information to guide them in managing the caregiving process (AARP \& National Alliance for Caregiving, 2015 [2]; LaValley, 
et al., 2019 [43]). In this study, working family caregivers requested support as categorized by the major themes of knowledge, understanding, and connection. Participants expressed a need for both factual information, such as financial and legal resources, and personal support to aid in decision making, provide insight into having difficult conversations, and create personal connections through support groups or phone consultations. Researchers have identified similar themes of support from spousal and adult children caregivers who evaluated the beneficial aspects of a community-based peer support program for caregivers (Zhou et al., 2020) [44].

The majority of participants in this study were caring for a parent and, as such, this relationship may have impacted the types of information and forms of support identified as beneficial. This notion is reinforced by findings in multiple studies that conclude the role of the caregiver can influence the types of aid sought (Grigorovich et al., 2016 [45]; Sundar et al., 2014 [46]; Wilcox, et al., 2001 [47]). In order to be truly supportive, assistance needs to match the individualized needs of the caregiver (Milliken et al., 2019) [48]. Furthermore, the ability to choose specific "services and supports empowers caregivers to make their own decisions and may reduce feelings of burden" (Sundar et al., 2014, p. 762) [46].

This study had several limitations. The population was a convenience sample, as participants volunteered through a local non-profit agency for aging. The population sample also lacked variability in demographics, as most of the participants were women from the same geographic area and the participants lacked diversity in race and socioeconomic status. Many components of the study also lacked variability in response, specifically related to the amount and duration of time spent caregiving. Variables such as the complexity of the impairment of the care recipient were not examined. Finally, the study has limited generalizability due to its small sample size (n-15) and having only examined caregivers who were employed full time.

\section{Implications}

Caregivers express a need for factual information and emotional support to aid them in their caregiving role that is beyond current workplace policies such as FMLA. Online tools, such as the online employee assistance support tool piloted in this study, can provide the factual, evidence based, and emotional support for which caregivers have expressed a desire. The online format provides greater accessibility by allowing sharing with multiple family members in different geographic areas to assist in the decision making process for needed supports. Employers can offer more individualized resources for their working caregiver employees to mitigate the negative impact the stress and burden of caregiving could have on the work environment. Future research should explore if the knowledge and supports provided by an online support tool for working caregivers can reduce the perceived caregiver burden, enhance the working caregiver's quality of life and make positive contributions to the workplace. 


\section{Conflicts of Interest}

The authors declare no conflicts of interest.

\section{References}

[1] National Alliance for Caregiving and Emblem Health (2010) Care for the Family Caregiver: A Place to Start.

http://www.caregiverslibrary.org/Portals/0/CGM.Care\%20for\%20the\%20Caregiver \%20-\%20A\%20place\%20to\%20startCFC.pdf

[2] American Association of Retired Persons (AARP) and National Alliance for Caregiving (2015) Caregivers of Older Adults: A Focused Look at Those Caring for Someone Age 50+.

https://www.aarp.org/content/dam/aarp/ppi/2015/caregivers-of-older-adults-focuse d-look.pdf

[3] Pew Research Center (2018) Adult Caregiving: Detailed Tables. Pew Research Center Analysis of 2012-2017 American Time Use Survey Data (IPUMS).

https://www.pewresearch.org/wp-content/uploads/2018/11/FT_18.11.09_Caregivers Tables1.pdf

[4] Matuska, K. and Barrett, K. (2014) Patterns of Occupation. In: Schell, B.A.B., Gillen, G. and Scaffa, M.E., Eds, Willard \& Spackman's Occupational Therapy, 12th Edition, Lippincott Williams \& Wilkins, Philadelphia, 163-172.

[5] Burton, W.N., Chen, C.Y., Conti, D.J., Pransky, G. and Edington, D.W. (2004) Caregiving for Ill Dependents and Its Association with Employee Health Risks and Productivity. Journal of Occupational and Environmental Medicine, 46, 1048-1056. https://doi.org/10.1097/01.jom.0000141830.72507.32

[6] Calvano, L. (2013) Tug of War: Caring for Our Elders While Remaining Productive at Work. Academy of Management Perspectives, 27, 204-218. https://doi.org/10.5465/amp.2012.0095

[7] Gaugler, J., Pestka, D., Davila, H., Sales, R., Owen, G., Baumgartner, S., Shook, R., Cunningham, J. and Kenney, M. (2018) The Complexities of Family Caregiving at Work: A Mixed-Methods Study. International Journal of Aging and Human Development, 87, 347-376. https://doi.org/10.1177/0091415017752936

[8] Lilly, M.B., LaPorte, A. and Coyte, P.C. (2007) Labor Market Work and Home Care's Unpaid Caregivers: A Systematic Review of Labor Force Participation Rates, Predictors of Labor Market Withdrawal, and Hours of Work. The Milbank Quarterly, 85, 641-690. https://doi.org/10.1111/j.1468-0009.2007.00504.x

[9] Liu, J., Lu, N. and Lou, V. (2017) Care Tasks in the Stress Process for Family Caregivers in Urban China. Clinical Gerontologist, 40, 428-434. https://doi.org/10.1080/07317115.2017.1305033

[10] Longacre, M.L., Valdmanis, V.G., Handorf, E.A. and Fang, C.Y. (2017) Work Impact and Emotional Stress among Informal Caregivers for Older Adults. Journals of Gerontology Series B: Psychological Sciences and Social Sciences, 72, 522-531. https://doi.org/10.1093/geronb/gbw027

[11] Paulson, D., Bassett, R., Kitsmiller, E., Luther, K. and Conner, N. (2017) When Employment and Caregiving Collide: Predictors of Labor Force Participation in Prospective and Current Caregivers. Clinical Gerontologist, 40, 401-412. https://doi.org/10.1080/07317115.2016.1198856

[12] Wolff, J.L., Spillman, B.C., Freedman, V.A. and Kasper, J.D. (2016) A National Profile of Family and Unpaid Caregivers Who Assist Older Adults with Health Care 
Activities. JAMA Internal Medicine, 176, 372-379. https://doi.org/10.1001/jamainternmed.2015.7664

[13] Fossey, E. (2019) Work as Occupation. In: Brown, C., Stoffel, V.C. and Muňoz J.P., Eds., Occupational Therapy in Mental Health: $A$ Vision for Participation, 2nd Edition, F.A. Davis Company, Philadelphia, 853-871.

[14] Hunt, L.A. (2015) Well-Being and Employment. In: Hunt, L.A. and Wolverson, C. Work and the Older Person: Increasing Longevity and Well-Being, SLACK Incorporated, Thorofare, 63-73.

[15] Cole, K., Daly, A. and Mak, A. (2009) Good for the Soul: The Relationship between Work, Wellbeing and Psychological Capital. Journal of Socio-Economics, 38, 464-474. https://doi.org/10.1016/j.socec.2008.10.004

[16] Stine-Morrow, E., Parisi, J., Morrow, D. and Park, D. (2008) The Effects of an Engaged Lifestyle on Cognitive Vitality: A Field Experiment. Psychology and Aging, 23, 778-786. https://doi.org/10.1037/a0014341

[17] Grossman, M.R. and Gruenewald, T.L. (2017) Caregiving and Perceived Generativity: A Positive and Protective Aspect of Providing Care? Clinical Gerontologist, 40, 435-447. https://doi.org/10.1080/07317115.2017.1317686

[18] Corvin, J., Chan, I., Tezak, A., Carpenter, K., Aguado Loi, C., Gonzales, J. and Hoare, I. (2017) Caring for Individuals with Chronic Illness and Minor Depression: Latino Perceptions of Caregiver Burden. Journal of Gerontological Social Work, 60, 79-95. https://doi.org/10.1080/01634372.2016.1268230

[19] Gray, K., Horowitz, B.P., O’Sullivan, A., Behr, S.K. and Abreu, B.C. (2007) Occupational Therapy's Role in the Occupation of Caregiving. OT Practice, 12, CE1-CE8.

[20] Pizzi, M.A. (2010) Promoting Health and Occupational Participation with Caregivers. In: Scaffa, M.E., Reitz, S.M. and Pizzi, M.A., Eds., Occupational Therapy in the Promotion of Health and Wellness, F.A. Davis Company, Philadelphia, 397-414.

[21] Schulz, R. and Eden, J. (Eds.) (2016) Families Caring for an Aging America. The National Academies Press, Washington. https://doi.org/10.17226/23606

[22] Schulz, R. and Tompkins, C.A. (2010) Informal Caregivers in the United States: Prevalence, Caregiver, Characteristics, and Ability to Provide Care. In: The Role of Human Factors in Home Health Care: Workshop Summary. National Academies Press, Washington DC. https://www.ncbi.nlm.nih.gov/books/NBK210048/

[23] Halpern, M.T., Fiero, M.H. and Bell, M.L. (2017) Impact of Caregiver Activities and social Supports on Multidimensional Caregiver Burden: Analyses from Representative Surveys of Cancer Patients and Their Caregivers. Quality of Life Research, 26, 1587-1595. https://doi.org/10.1007/s11136-017-1505-9

[24] Thornton, M. and Travis, S.S. (2003) Analysis of the Reliability of the Modified Caregiver Strain Index. The Journals of Gerontology. Series B, 58, S127-S132. https://doi.org/10.1093/geronb/58.2.S127

[25] Zarit, S.H. and Zarit, J.M. (2015) Family Caregiving. In: Bensadon, B.A., Ed., Psychology and Geriatrics: Integrated Care for an Aging Nation, Elsevier, New York, 21-43. https://doi.org/10.1016/B978-0-12-420123-1.00002-2

[26] Barrett, L. (2013) Caregivers: Life Changes and Coping Strategies. American Association of Retired Persons, Washington DC.

https://www.aarp.org/research/topics/care/info-2014/caregivers-life-changes-and-c oping-strategies.html

[27] Cooper, C., Katona, C., Orrell, M. and Livingston, G. (2008) Coping Strategies, Anxiety and Depression in Caregivers of People with Alzheimer's Disease. Interna- 
tional Journal of Geriatric Psychiatry, 23, 929-936. https://doi.org/10.1002/gps.2007

[28] Sun, F., Kosberg, J.I., Kaufman, A.V. and Leeper, J.D. (2010) Coping Strategies and Caregiving Outcomes among Rural Dementia Caregivers. Journal of Gerontological Social Work, 53, 547-567. https://doi.org/10.1080/01634372.2010.496823

[29] Van Dongen, I., Josephsson, S. and Ekstam, L. (2014) Changes in Daily Occupations and the Meaning of Work for Three Women Caring for Relative's Post-Stroke. Scandinavian Journal of Occupational Therapy, 21, 348-358. https://doi.org/10.3109/11038128.2014.903995

[30] U.S. Department of Labor (2019) Family and Medical Leave Act (FMLA). https://www.dol.gov/general/topic/workhours/fmla

[31] Yang, Y.T. and Gimm, G. (2013) Caring for Elder Parents: A Comparative Evaluation of Family Leave Laws. The Journal of Law, Medicine and Ethics, 41, 501-513. https://doi.org/10.1111/jlme.12058

[32] Chen, M. (2016) The Growing Costs and Burden of Family Caregiving of Older Adults: A Review of Paid Sick Leave and Family Leave Policies. The Gerontologist, 56, 391-396. https://doi.org/10.1093/geront/gnu093

[33] Administration for Community Living (2019) National Family Caregiver Support Program.

https://acl.gov/programs/support-caregivers/national-family-caregiver-support-pro gram

[34] Jang, S.J., Park, R. and Zippay, A. (2010) The Interaction Effects of Scheduling Control and Work-Life Balance Programs on Job Satisfaction and Mental Health. International Journal of Social Welfare, 20, 135-143. https://doi.org/10.1111/j.1468-2397.2010.00739.x

[35] Dembe, A. and Partridge, J. (2011) The Benefits of Employer-Sponsored Elder Care Programs: Case Studies and Policy Recommendations. Journal of Workplace Behavioral Health, 26, 252-270. https://doi.org/10.1080/15555240.2011.589755

[36] Ireson, R., Sethi, B. and Williams, A. (2018) Availability of Caregiver-Friendly Workplace policies (CFWPs): An International Scoping Review. Health \& Social Care in the Community, 26, e1-e14. https://doi.org/10.1111/hsc.12347

[37] Onega, L.L. (2008) Helping Those Who Help Others: The Modified Caregiver Strain Index (MCSI). American Journal of Nursing, 108, 62-69. https://doi.org/10.1097/01.NAJ.0000334528.90459.9a

[38] Nowell, L.S., Norris, J.M., White, D.E. and Moules, N.J. (2017) Thematic Analysis: Striving to Meet Trustworthiness Criteria. International Journal of Qualitative Methods, 16, 1-13. https://doi.org/10.1177/1609406917733847

[39] Lincoln, Y. and Guba, E.G. (1985) Naturalistic Inquiry. Sage, Newbury Park.

[40] Cambridge University Press's Online Dictionary (n.d.) Knowledge. https://dictionary.cambridge.org/us/dictionary/english/knowledge

[41] National Alliance for Caregiving and AARP Public Policy Institute (2015) Caregiver Profile: The Typical Caregiver.

https://www.aarp.org/content/dam/aarp/ppi/2015/AARP1001_Typical_CGProfileA ug26.pdf

[42] Cronin, A. (2016) Middle Adulthood. In: Cronin, A. and Mandich, M., Eds., Human Development and Performance throughout the Lifespan, 2nd Edition, Cengage Learning, Boston, 379-404.

[43] LaValley, S.A., Vest, B.M. and Hall, V. (2019) Challenges to and Strategies for Formal Service Utilization among Caregivers in an Underserved Community. Journal 
of Gerontological Social Work, 62, 108-122.

https://doi.org/10.1080/01634372.2018.1542372

[44] Zhou, D.R., Hung, S. and Ting Lo, T.L. (2020) Can We Hit Two Birds with One Stone: An Effectiveness Study of Peer-Support Groups for Low-Income Spousal and Adult Children Caregivers of Hong Kong Older Adults. Journal of Gerontological Social Work, 63, 227-249. https://doi.org/10.1080/01634372.2020.1746722

[45] Grigorovich, A., Rittenberg, N., Dick, T., McCann, A., Abbott, A., Kmielauskas, A., Estioko, V., Kulasingham, S. and Cameron, J.I. (2016) Roles and Coping Strategies of Sons Caring for a Parent with Dementia. American Journal of Occupational Therapy, 70, Article ID: 7001260020. https://doi.org/10.5014/ajot.2016.017715

[46] Sundar, V., Fox, S.W. and Phillips, K.G. (2014) Transitions in Caregiving: Evaluating a Person-Centered Approach to Supporting Family Caregivers in the Community. Journal of Gerontological Social Work, 57, 750-765.

https://doi.org/10.1080/01634372.2013.847885

[47] Wilcox, S., O’Sullivan, P. and King, A. (2001) Caregiver Coping Strategies: Wives versus Daughters. Clinical Gerontologist, 23, 81-97.

https://doi.org/10.1300/J018v23n01_08

[48] Milliken, A., Mahoney, E.K., Mahoney, K.J., Mignosa, K., Rodriguez, I., Cuchetti, C. and Inoue, M. (2019) "I'm Just Trying to Cope for Both of Us": Challenges and Supports of Family Caregivers in Participant-Directed Programs. Journal of Gerontological Social Work, 62, 149-171. https://doi.org/10.1080/01634372.2018.1475438 